\title{
Analysis on Technology Competitiveness in Fuel Cell Field
}

\author{
Young-Il Kwon and Dae-Hyun Jeong, Member, IACSIT
}

\begin{abstract}
Fuel cell is an environment-friendly renewable energy source. Major countries that are trying to diversify their power supply are expanding their technology development and efforts to spread the usage of fuel cell. In this study, the level of usage in each country was analyzed through technology competitiveness analysis on fuel cell. To analyze technology competitiveness, total four elements of influence, competitiveness, activity, and open innovation were considered. Influence was calculated using forward citation of applied patent, and competitiveness was calculated using the number of patent family. For open innovation, joint application network between countries was settled and analysis was made through degree centrality. In the result, besides MCFC field, USA was found to be the most competitive, while Japan and Korea were found to be relatively less competitive. When it was studied by a major element, USA had a high level of competitiveness and open innovation, and Canada had high level of influence.
\end{abstract}

Index Terms-Competitiveness, fuel cell, network analysis.

\section{INTRODUCTION}

Fuel cell is an environment-friendly renewable energy source with higher system efficiency than other energy sources. It does not produce noise, require a separate engine, release sulfur, NOx. Major countries that try to diversify power source are expanding efforts to develop and spread the technology. Following the greenhouse gas reduction plan, major countries related to fuel cell are paying attention to fuel cell for transportation and fuel cell for building requiring less area with high efficiency. Recently in Korea, the government suggested a strategy to introduce fuel cell following power supply plan, and fuel cell electric vehicle(FCEV) is being developed through green car fostering plan.

The market size of this fuel cell is expected to reach US \$ 11.8 billion dollar in 2020 and to grow to US \$ 16.2 billion dollar in 2030. In addition, spread of stationary fuel cell was about 54.6MW for 2011, taking $64 \%$ of total fuel cells. Accumulated sales volume of fuel cell electric vehicle is expected to exceed 1.2 million cars by 2020 . Area of fuel cell is the area urgently requiring national support [1]. The purpose of this study is to analyze technical level of fuel cell development and present the technical competitiveness of each country.

In general, technology level evaluation is a study to compare and evaluate scientific technology, industrial technology of multiple subjects of country, industry, and

Manuscript received June 21, 2013; revised December 20, 2013. This work was supported by the National Research Foundation of Korea Grant founded by the Korean Government (MSIP) (2013M1A2A3000319).

The authors are with KISTI, Seoul, Korea (e-mail: gregori79@ kisti.re.kr). corporation. In Korea, experts are actively studying technology level evaluation in a macroscopic level. However, while the qualitative method like this is easy to study, its limit is always proven to depend on too much on opinion of experts. To overcome the qualitative limitation, studies on technology level evaluation using various quantitative methods are being made [2].

Among these, patent index is objective and standard technology information and useful to view not only the technology level and innovation flow but also the technology innovation trend [3]. In general, patent index includes specific contents related to the latest technology. With a patent index, technology information in various fields can be acquired easily, and is easy to use because Data Base is well constructed [4]. However, existing patent analysis method is limited to evaluate a technology level in macroscopic level for a country, industry, since it only uses certain index to evaluate the technology level. Accordingly, organizations like Korea Evaluation Institute of Industrial Technology developed a complex patent index of AIMS + consisting of patent activity, patent concentration, patent market capacity, and patent influence and conducted macroscopic technology level evaluation on IT industry [5]. However, this AIMS+ has a limit as a certain index is deducted through a common individual index.

Since patent information data is obtained through patent search, patent data with unnecessary contents are included. Unnecessary data is called noise and it takes long to remove noise data. Studies have been conducted actively to improve such works [6].

In this study, we evaluated technology level in fuel cell field by country by checking current status of joint patent application in the analysis of existing indices of patent activity, patent influence and patent market capacity.

Open innovation is achieved through joint development between corporations for creation of value using both outside and inside ideas in order to accelerate internal innovation and to develop technology [7].

That is, open innovation is the innovation methodology of corporation that utilizes external resources by opening a series of innovation process from research, development, to commercialization, and maximizes the creation of added value by reducing costs for innovation and improving possibility of success.

In addition, Chesbrough explained the concept of open innovation in comparison to close innovation. Open innovation includes introduction of external technology inside the corporation and commercialization of technology inside corporation through another external path with smooth exchange of knowledge inside and outside the corporation for each stage of research, development and commercialization. 
Open innovation can be divided into introvert and extrovert openings. The former indicates acquisition of technology or idea from outside in the process of technology innovation and the latter means exploring of commercialization through other path rather than existing business model. Types of introvert opening and extrovert opening are summarized in Table I [8].

TABLE I: TYPES OF OPEN INNOVATION

\begin{tabular}{cc}
\hline \hline Tntrovert Opening & Extrovert Opening \\
\hline Joint study & Sales of technology \\
Study contract & Spin off \\
Establishment of joint venture & \\
Acquisition of corporation & \\
Collaborative intelligence & \\
\hline \hline
\end{tabular}

Knowledge environment surrounding corporation has changed and change in knowldge environment has been accelerated since 1980. In this regard, open innovation has been regarded as the required element rather than a selective element and considered as the most crucial factor in technology development for creation of future foods.

\section{STUDY METHOD}

In this study, we added index related to open innovation to patent activity, technical competiveness, patent impact used as existing patent indices to evaluate the technology level in the area of fuel cell, and analyzed them. Patent activity was analyzed through patent activity index of the relevant company in the fuel cell technology and definition of patent activity index is as follows.

$$
\text { Activity Index }=\frac{A / B}{C / D}
$$

$A=$ number of patent application of specific applicants in the specific technology area.

$B=$ number of patent application in specific technology area.

$C=$ total number of patent applications of specific applicants.

$D=$ total number of patent applications.

Technical competiveness was analyzed through the number of family patent, and patent impact through number of patent citation of the relevant country in the area of fuel cell. The reason why technical competiveness was measured with the number of family patent is because higher number of family patents means higher efforts to secure market and higher number of family patents also means higher technical competiveness.

The following is the definition of patent family index that evaluates technical competiveness.

$$
\text { Patent Family Index }=\frac{A}{B}
$$

$A=$ number of family patent, $B=$ total number of patents.

The reason why patent impact was calculated using the number of patent citation is because the number of patent citation shows how much it is cited by the other patent and that more citation is close to source study and considerably affect the other patents [9].

The following is the definition of patent citation index that evaluates patent impact.

$$
\text { Cites Per Patent }=\frac{A}{B}
$$

$A=$ number of citation, $B=$ total number of patents

Studies on patent index have been developed using patent bibliographic information. Citation information has been used as the main index representing the qualitative performance of patents. Studies have been conducted actively including studies on development of importance evaluation model of patent using citation information, studies on patent citation prediction model using citation information, studies on method to predict the technology life of specific area and studies on development of patent index in consideration of technology impact index of patent application institutions and citation information [10]-[14].

Open innovation can be shown through present status of joint application between countries in the area of fuel cell. For this purpose, national network of joint applicants has been implemented and level of open innovation per country has been identified using the value of centrality degree per country.

Social network refers to the network of people by a series of relations and is established based on social relations.

Matrix is used for network analysis and has the basic concept of indicating existence or non-existence of relation of matrix $(i, j)$ as 1 or 0 in expressing the terms of matrix from $i$ to $j$. Network analysis has different analysis index and analysis elements depending on the level to analyze. It can be separated into Centrality from microscpic level, Structural Equivalence from intermediate level, Density and Size in microscopic level. Differentiated data is collected analyzed depending on the level and targets of analysis.

Goal of network analysis is to recognize the relation between social existences such as individual, organization, country, and to find the contents and shape of network structure. Interaction between nodes in the system is analyzed through visual expression of graph technique. Using the concrete concepts such as Density, Centrality and Structural Equivalence utilized for network analysis, social relationship, connection relation and network are analyzed quantitatively. Social Network Analysis (SNA) or connection network theory is utilized in the organization theory and policy network studies.

This study examined the analytical elements from microscopic level and analyzed with application of network theory focusing on the degree centrality index. Degree centrality used in this thesis indicates whether there are many or less connected nodes by measuring how central one node is located at the network and measuring the connection degree of one node of network with other node connected directly with this. Connection degree centrality evaluating the open innovation was calculated with the following formula [15].

$$
D_{c}\left(p_{k}\right)=\frac{\sum_{i=1}^{n}\left(p_{i} \times p_{k}\right)}{n-1}
$$

where $D_{c}\left(p_{k}\right)=$ degree centrality of $p_{k}$ 
$p_{i} \cdot p_{k}=$ number of nodes that appears at row $i$ and $k$.

$n=$ total number of nodes.

\section{PATENT ANALYSIS METHOD}

For patent information related to fuel cell used in this study, data was extracted using was WINTELIPS provided by WIPS and analysis was made to patents related to fuel cell applied in Korea, USA, Japan, Europe, China and international patents from 2000 to May 2012. (Shown in Table II)

TABLE II: NUMBER OF PATENTS AND ANALYSIS SECTION

\begin{tabular}{cccc}
\multicolumn{3}{c}{ PER COUNTRY } \\
\hline \hline Classification & Country & Total Period & $\begin{array}{l}\text { Patents for Analysis } \\
\text { (cases) }\end{array}$ \\
\hline & Korea & & 1,909 \\
Open/ & USA & & 4,076, \\
Registered & Japan & 2000.1 .1 & 7,162 \\
Patent & Europe & 2012.5 .31 & 1,228 \\
& China & & 3,190 \\
& Internatio & & 1,896 \\
& nal & & 19,461 \\
\hline Total & & \\
\hline
\end{tabular}

To implement the network between countries for each area of fuel cell, synchronous matrix was created for the 1 st applicant and 2nd applicant and network was implemented using NetMinder 3.0 developed by Cyram.

NetMiner is the software developed for research/study and professional analysis using social network analysis. In addition, NetMiner includes visualization module and analysis model related to social network analysis, and was developed to help users to effectively analyze using network data and visualization outcome [16].

\section{RESULTS}

When patent application trend by nationality of applicant in fuel cell field was studied, Japan applied the most patents, followed by USA, Korea, Germany and Canada. (See Fig. 1).

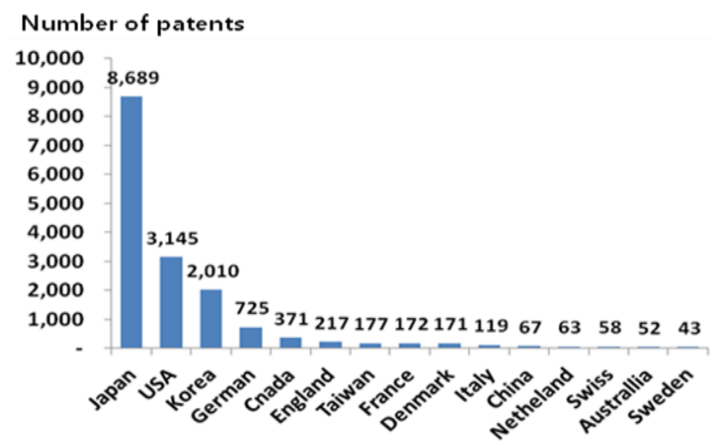

Fig. 1. Trend of fuel cell patent application by country.

In terms of changes in patent activity in main countries for each area of fuel cell, China (in PEMFC), USA and France (SOFC), Italy (MCFC), Italy, Germany and France (DMFC) are found to focus on research and development since 2005. (See Fig. 2-Fig. 5).

In particular, as Japan showed no big difference in patent activity for PEMFC area, research and development has been carried out steadily. In Korea, patent activity for MCFC was found relatively high, but analyzed to show no big difference from other technology.

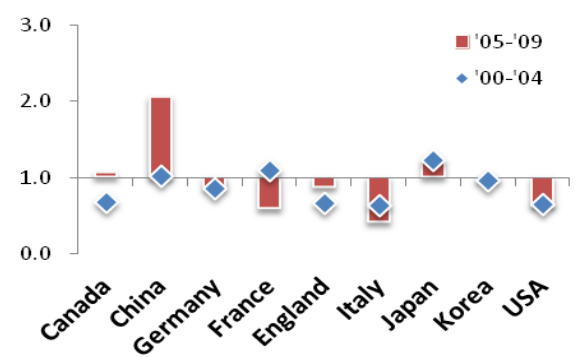

Fig. 2. Patent activity change of main countries in PEMFC.

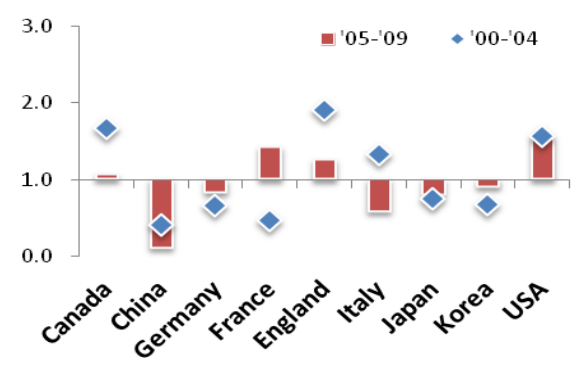

Fig. 3. Patent activity change of main countries in SOFC.

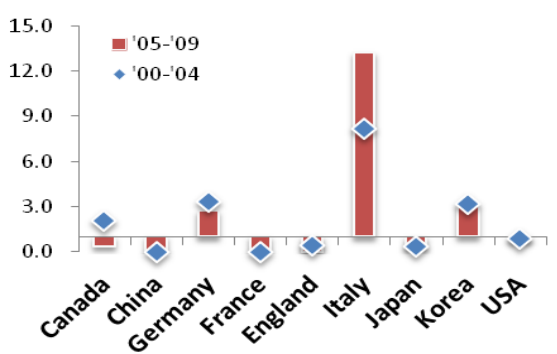

Fig. 4. Patent activity change of main countries in MCFC.

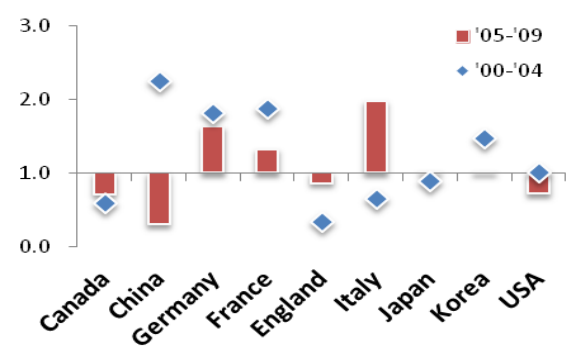

Fig. 5. Patent activity change of main countries in DMFC.

In terms of qualitative level and market share per nationality of main applicants, patent quality level and market share of Australia, Germany and Demark applicant were found to be high.

In case of American applicant, CPP (Cites Per Patent) was higher than average, showing qualitatively excellent patent. Korea showed qualitative level and market share index (PFS: Patent Family Size) lower than average, indicating that continuous research and development are required. (See Fig. 6)

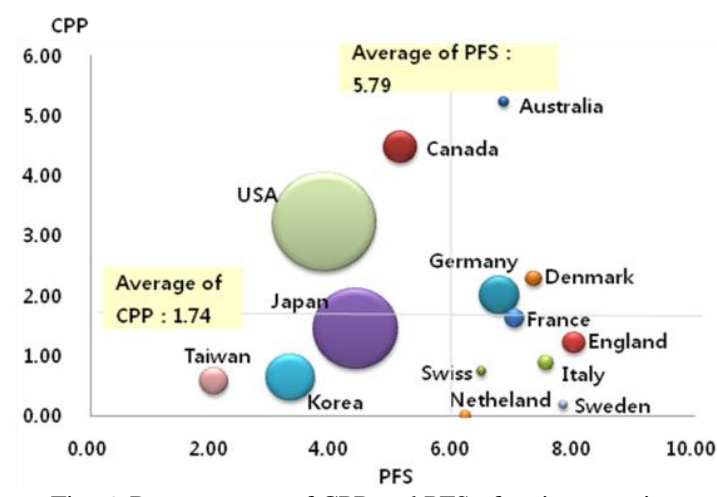

Fig. 6. Present status of CPP and PFS of main countries. 
For analysis of total competitiveness in the area of fuel cell, top 5 countries that applied the highest number of patents were analyzed. As mentioned earlier, competitiveness analysis was conducted in a total of four areas. Patent impact was analyzed through degree of citation of patents and technical competiveness through the number of family patents. Patent activity was analyzed through activity index. In addition, open innovation was measured through degree centrality from the joint study status network for each country.

As a result, USA was found to have the highest technical competitiveness in the area of PEMFC and DMFC, and Canada in the area of SOFC and MCFC. Korea was found to have low technology level compared to the highest competitiveness in the area of fuel cell. Recording the highest number of patents in the area of fuell cell, Japan also was found to have low technical competiveness in the qualitative aspect.

Overall technical competitiveness in the area of fuel cell per country was analyzed using the country that has the highest technical competiveness in the relevant area as 1 . (Shown in Table III).

TABLE III: ANALYSIS OF OVERALL COMPETITIVENESS IN FuEL CELL PER COUNTRY

\begin{tabular}{ccccc}
\hline \hline & PEMFC & SOFC & MCFC & DMFC \\
\hline Canada & 0.76 & 1.00 & 1.00 & 0.61 \\
Germany & 0.93 & 0.58 & 0.60 & 0.70 \\
Japan & 0.49 & 0.28 & 0.12 & 0.35 \\
Korea & 0.44 & 0.27 & 0.39 & 0.42 \\
USA & 1.00 & 0.67 & 0.63 & 1.00 \\
\hline \hline
\end{tabular}

It was analyzed using a total of four points as perfect score regarding the patent impact, technical competiveness, patent activity and open innovation in the area of fuel cell.

As a result, in the area of PEMFC, USA was found to have highest overall competitiveness, followed by Germany and Canada. USA was found to have evenly high level in terms of patent impact, technical competiveness and open innovation, while Germany was analyzed to have higher competitiveness in terms of patent activity rather than patent impact. (See Fig. 7).

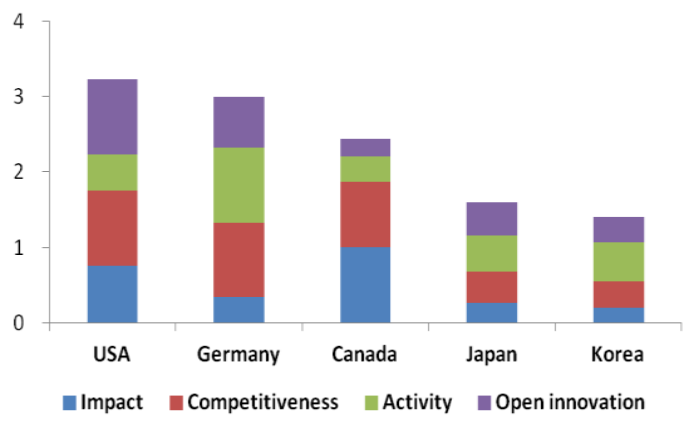

Fig. 7. Analysis of overall competitiveness in PEMFC.

In SOFC, Canada was found to have highest technical competitiveness and evenly high level in the area of patent impact, technical competiveness, patent activity and open innovation. Korea was found to have relatively high score at patent activity and open innovation. (See Fig. 8).

In MCFC, Canada was found to have the highest technical competitiveness and evenly high scores in the area of patent impact, technical competiveness and open innovation. (See Fig. 9).

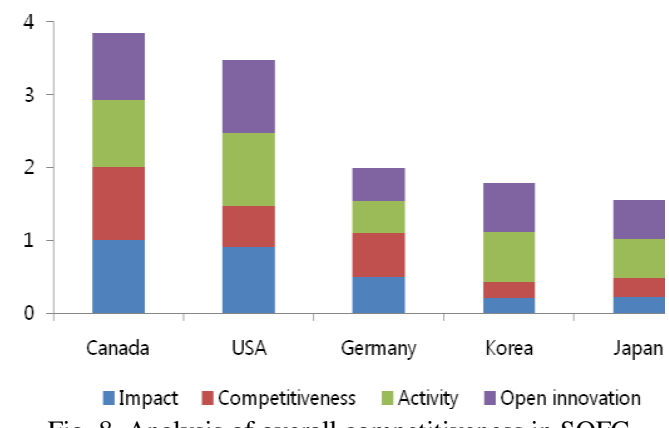

Fig. 8. Analysis of overall competitiveness in SOFC.

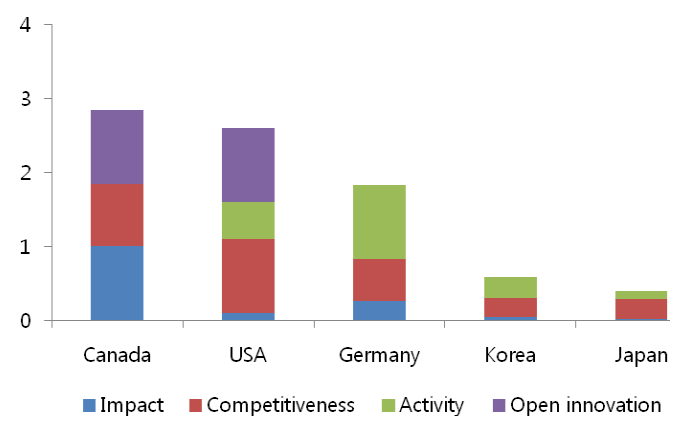

Fig. 9. Analysis of overall competitiveness in MCFC.

In DMFC, USA was found to have the highest technical competitiveness and to have relatively high scores in the area of patent impact, technical competiveness and open innovation. (See Fig. 10).

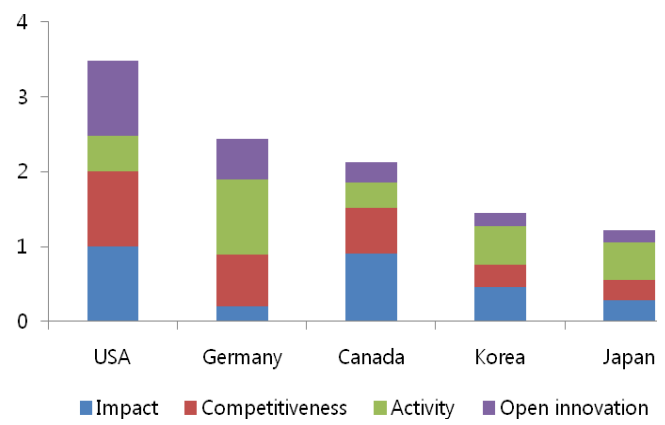

Fig. 10. Analysis of overall competitiveness in DMFC.

Present status on joint application per fuel cell area was analyzed through network analysis (See Fig. 11-Fig. 14).

In PEMFC, USA was found to have reinforced joint studies with Germany, Canada and Japan, while Korea reinforced joint studies with Japan.

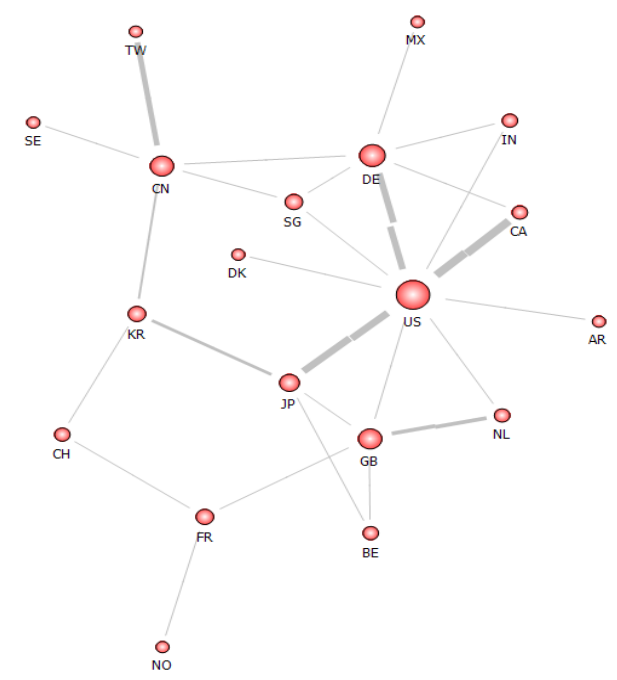

Fig. 11. Joint application network between countries in PEMFC. 
As a result of network analysis in PEMFC, the degree centrality was found to be highest in USA, playing the central role in joint studies, followed by Germany, China and UK. (Shown in Table IV)

\begin{tabular}{ccc}
\multicolumn{2}{c}{ TABLE IV: TOP 10 COUNTRIES OF DEGREE CENTRALITY IN PEMFC } \\
\hline \hline Node & Country & Degree Centrality \\
\hline US & USA & 0.30 \\
DE & Germany & 0.20 \\
CN & China & 0.17 \\
GB & England & 0.17 \\
JP & Japan & 0.13 \\
SG & Singapore & 0.10 \\
FR & France & 0.10 \\
KR & Korea & 0.10 \\
IN & India & 0.07 \\
\hline
\end{tabular}

In SOFC, USA was found to have reinforced joint studies with Germany, Holland, Japan and Canada, while Korea with USA and Japan.

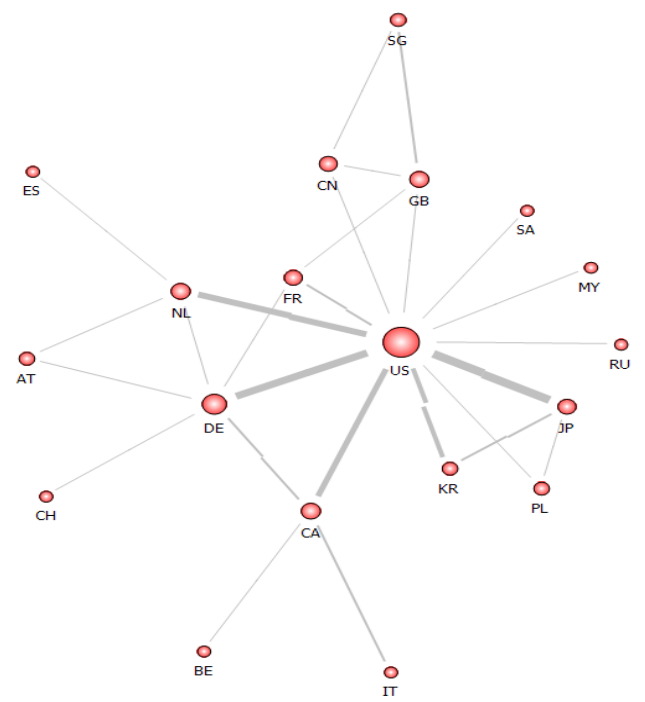

Fig. 12. Joint application network between countries in SOFC.

As a result of analyzing network in SOFC, USA was found to have the highest degree centrality, playing the central role in joint studies, followed by Germany, Holland, UK and Canada. (Shown in Table V)

TABLE V: TOP 10 COUNTRIES OF DEGREE CENTRALITY IN SOFC

\begin{tabular}{ccc}
\hline \hline Node & Country & Degree Centrality \\
\hline US & USA & 0.40 \\
DE & Germany & 0.20 \\
NL & Holland & 0.13 \\
GB & England & 0.13 \\
CA & Canada & 0.13 \\
CN & China & 0.10 \\
FR & France & 0.10 \\
JP & Japan & 0.10 \\
KR & Korea & 0.07 \\
SG & Singapore & 0.07 \\
\hline \hline
\end{tabular}

In DMFC, USA was found to have reinforced joint studies with Japan, while Korea with Japan.

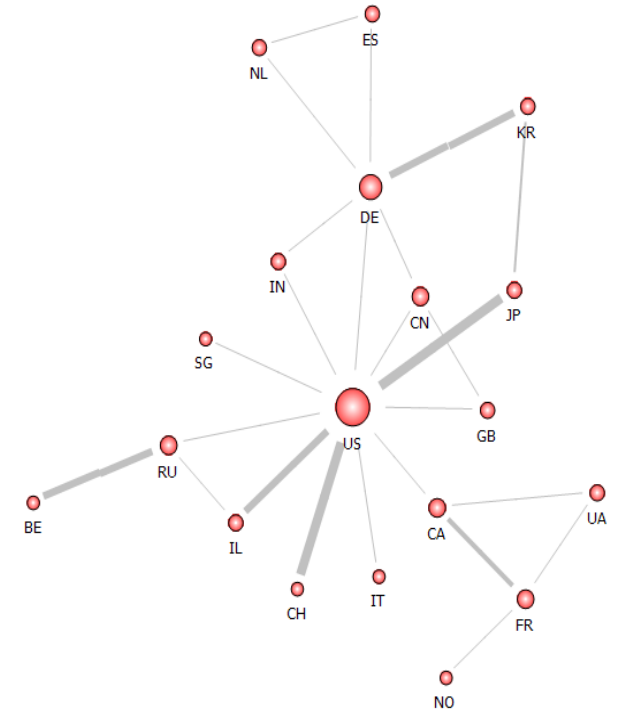

Fig. 13. Joint application network between countries in DMFC.

As a result of analyzing network in DMFC show in Table VI, USA was found to have the highest degree centrality, playing the central role in joint studies, followed by Germany and China.

TABLE VI: TOP 10 COUNTRIES OF DEGREE CENTRALITY IN DMFC

\begin{tabular}{ccc}
\hline \hline Node & Country & Degree Centrality \\
\hline US & USA & 0.41 \\
DE & Germany & 0.22 \\
CN & China & 0.11 \\
RU & Russia & 0.11 \\
CA & Canada & 0.11 \\
FR & France & 0.11 \\
IN & India & 0.07 \\
NL & Holland & 0.07 \\
ES & Spain & 0.07 \\
KR & Korea & 0.07 \\
\hline \hline
\end{tabular}

In MCFC, no joint studies were conducted actively, and joint study between USA and Holland was carried out.

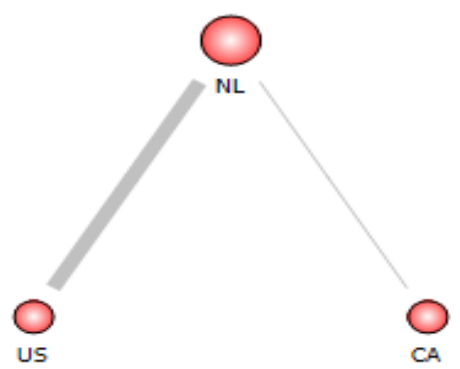

Fig. 14. Joint application network between countries in MCFC.

\section{CONCLUSION}

We analyzed technical competitiveness of each country in fuel cell field, using patents related to fuel cell. As a result, USA and Canada were found to possess the top level technology in all fields, showing that North American Region is the area where technology level of fuel cell takes the lead.

On the contrary, Japan with a large number of patents was 
analyzed to have very low technology competitiveness. Korea was found to have low technology competitiveness in every field, especially, the country was found to stay at $20 \sim 40 \%$ of top technology country in technology influence.

To develop the fuel cell field in the future, first, efforts should be made to develop core technology in order to enhance influence and for open innovation activity, it is required to make more efforts to activate joint studies with USA with high technology level in the area of PEMFC, SOFC and DMFC, and with Canada with high technology level in the area of DMFC.

However, the technology competitiveness analysis performed in this study has some limitations. First, in a country with a large fuel cell market, patent application is made mainly within the country, reducing the technology competitiveness. However, in this case, the actual technology level of the country cannot be convinced as low status and large markets means that reflect high technology capacity in the relevant field. And, when the level of a technology in a field itself is not matured enough to drive joint research, deciding the degree of open innovation by analyzing joint research can be unreasonable. Accordingly, to make a reliability analysis of relevant technology field in the future, a comparative analysis study with existing qualitative technology level result is required.

\section{ACKNOWLEDGMENT}

This work was supported by the National Research Foundation of Korea Grant founded by the Korean Government (MSIP) (2013M1A2A3000319).

\section{REFERENCES}

[1] D. H. Jung and Y. I. Kwon, 2012 Green Technology Knowledge Map-Fuel Cell, Korea Institute of Science and Technology Information, 2012.

[2] M. K. Han, B. S. Kim, J. Y. Yu, and S. C. Byun. "Result and implication of technology level evaluation based on technology growth model: focusing on bio-chip and sensor technology," Korea Technology Innovation Society Journal, vol. 13, no. 2, pp. 252-281, June 2010.

[3] W. H. Lee, K. Jung Ahn, and M. H. Lee, "Technology innovation in Korea through patent citation analysis," in Proc. Korean Operations Research and Management Science Society Full Conference, 2003, pp. 1007-1013.
[4] H. K. Jung and K. S. Hwang, "Technology competitiveness analysis of aviation base industry using patent information," Journal of Management Science, vol. 25, no. 2, pp. 111-127, Nov. 2008

[5] Korea's IT Technology Competitiveness Analysis Report Using Measurement Information, Korea Evaluation Institute of Industrial Technology, 2011

[6] H. S. Gang and S. H. Lee, "A study on evaluation of patent technology level with improved reliability as well as effective noise removal in patent data analysis," Journal of Korea Technology Innovation Society, vol. 15, no. 1, pp. 105-128, March 2012.

[7] H. Chesbrough, "Open innovation: how companies actually do it," Harvard Business Review, vol. 81, no. 7, pp. 12-14, July 2009

[8] S. K. Kim, "Is open innovation new innovation methodology?: critical evaluation on open innovation theory of chesbrough," Technology Management and Economy Association, pp. 123-154, Feb 2009.

[9] Development and Application of Technology Level Evaluation Research Methodology Using Patent Index, Korea Institute of S\&T Evaluation and Planning, 2011.

[10] J. B. Yu and Y. M. Jung, "Analysis of Factors of Patent Citation," Journal of Information Management Association, vol. 27, no. 1, pp. 103-118, March 2010.

[11] H. Kim, D. H. Baek, M. J. Shin, and D. S. Han, "Technical importance evaluation model of patent under incomplete citation information," Intelligent Information Study, vol. 14, no. 2, pp. 121-136, March 2006

[12] J. B. Yu and Y. M. Jung, "A study on construction of patent citation prediction model," Journal of Information Management Association, vol. 27, no. 4, pp. 239-258, 2010.

[13] S. H. Yu, Y. H. Lee, and D. K. Won, "A study on life prediction of technology area through analysis of patent citation," Journal of Korea Management Association, vol. 31, no. 4, pp. 1-11, March 2006.

[14] Y. J. Nam and E. S. Jung, "A study on development of new patent index using citation information," Journal of Information Management Association, vol. 23, no. 1, pp. 221-241, March 2006.

[15] D. W. Son, Analysis of Social Network, Kyungmun Sa, 2010, pp.1-3.

[16] K. H. Kim, Analysis of Social Network using Netminer, Cyram, 2010.

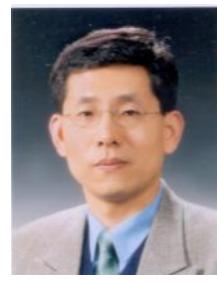

Young-Il Kwon was born in October 1962, Seoul, Korea. He got his Ph.D in mechanical engineering at Sungkyunkwan University in August 2001.

He works at KISTI as a principal researcher. KISTI is located in Seoul, Korea.

Dr. Kwon's areas of interests are text-mining, renewable energy technologies and analysis of information. He is a member of IACSIT.

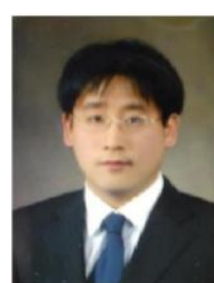

Dae-Hyun Jeong was born in Seoul, Korea in November 1979. He got the degree of master of material engineering at Hanyang University which is located in Seoul, Korea in August 2009.

He works at KISTI, Seoul, Korea as a researcher.

Mr. Jeong's areas of interests are data-mining, analysis of information and social network analysis. This author is a member of IACSIT. 